\title{
EL DEVENIR MINORITARIO COMO CLAVE DE LECTURA EN LAS POÉTICAS NEOBARROCAS DE NÉSTOR PERLONGHER Y ANTONIO SILVA ${ }^{1}$
}

\author{
Biviana Hernández $O$. \\ Pontificia Universidad Católica de Chile \\ biviana.hernandezz@gmail.com
}

\section{RESUMEN / ABSTRACT}

En este artículo propongo una lectura en clave neobarroca de las poéticas de Néstor Perlongher y Antonio Silva, en tanto escrituras de la violencia sexual, política y sublime a la que el cuerpo como ficción anatómica es sometido. Para ello utilizaré la noción de "devenir minoritario" como espacio crítico de verbalización de la otredad (devenir mujer, travesti, homosexual, indígena), y, en tanto que tal, como margen territorial y político desde donde problematizar las demarcaciones estético-simbólicas del poder y la ideología, sus sistemas de control sobre los cuerpos y mecanismos de dominio, aparentemente más “democráticos" del mundo social contemporáneo.

Palabras clave: escritura neobarroca, otredad, devenir minoritario, Néstor Perlongher, Antonio Silva.

In this article I propose a neo-baroque key reading of Néstor Perlongher's and Antonio Silva's poetics. I mean a writing of sexual, political and sublime violence to which the body, as an anatomic fiction, is subjected to. For this purpose, I will exploit the notion of "minoritary becoming" as the otherness's critical verbalization space; and as such, as a territorial and political boundary from where is possible to question Power's aesthetical-symbolic limits and hegemonic discourses of control over the bodies and sexualities.

KEYWORDS: neo-baroque writing, otherness, minoritary becoming, Néstor Perlongher, Antonio Silva.

Este artículo forma parte del Proyecto FONDECYT de Postdoctorado \#3130628: "Poesía y neovanguardias: textualidades para un nuevo repertorio", del cual soy investigadora responsable. 


\section{A MODO DE INTRODUCCIÓN}

Allí donde Luz Ángela Martínez percibe el entramado transhistórico y cultural de unas "constantes barrocas" en la era actual, Sergio Rojas postula "lo barroco" como un fenómeno inherente a la literatura y el arte de la modernidad en tanto reflexión sobre los recursos representacionales. La obra neobarroca como autoconciencia poética inscribe su pertenencia a la literatura ya como un género o un tipo de discurso que hace referencia al código formal que la genera. Toda obra de arte en la modernidad, arguye Rojas, es a la vez un concepto sobre el género de producción en el que se inscribe y desde el cual se origina. Lecturas que se inscriben en el horizonte más amplio de lo que Omar Calabrese definió como un fenómeno cultural en la "actualidad": el neobarroco, como un ciclo fracasado de modernización tras la crisis del proyecto de industrialización y la reinserción de América Latina en el capitalismo y mercado mundiales, a través de la total apertura de sus economías; situación que daría al neobarroco la posibilidad de otra lectura, la de un campo cultural, teórico y literario radicalmente diferente de aquel, que en las décadas de los 30 y 60, marcaba la existencia del primer renacimiento del barroco, de acuerdo a la emergencia de proyectos nacionales de modernización. Para las tres últimas lecturas, en tanto, frustrada la operatividad/aplicación de estos proyectos, se contaría con otras determinantes del contexto en que resurgiría el neobarroco como el período de un segundo renacimiento del barroco: el despliegue de la cultura de masas, el surgimiento de los estudios culturales y su contribución a la redefinición del estatuto de la literatura y las artes, la emergencia de discursos y teorías interdisciplinarios, la importancia creciente de la circulación, consumo y recepción de la obra artística, convertida en producto y mercancía cultural, entre muchas otras, que harían que esta "última" constante del neobarroco latinoamericano surgiera en el marco de un nuevo renacimiento a escala global en las tres últimas décadas del siglo $\mathrm{XX}$, en el contexto de la, así llamada, crisis de la modernidad, la consecuente emergencia del discurso postmoderno y las múltiples lecturas crítico-teóricas en torno a su estatuto.

En el contexto que implican las exploraciones literarias y, específicamente poéticas, del campo cultural latinoamericano en este periodo, Eduardo Milán ha sostenido que el neobarroco no constituye un nuevo barroco, como tampoco un barroco emergente, sino el barroco posible en el contexto de la escritura poética de "este" momento histórico, afín a la concepción de Bolívar Echeverría, quien lo entendiera, a partir de una lectura "situada", como 
actitud o modo de actuar en la coyuntura histórica del capitalismo tardío. Allí donde texto y actitud neobarrocos implican referirse a una emergencia, que define un perfil residual, esto es, algo que ocurre luego de prácticas poéticas radicales que marcarían, a partir de la década de los 50, el devenir de la poesía latinoamericana (poesía concreta y antipoesía, por mencionar solo dos importantes manifestaciones), tras la huella de acontecimientos históricos que fortalecieron su profundidad por su accionar sobre un contexto sociopolítico radicalmente tensionado y convulso (no olvidemos el efecto de largo aliento que produjo la estela de dictaduras militares en toda la región).

Para Milán, la propuesta de una escritura neobarroca no responde más a un movimiento estético organizado y sistemático que a la tentativa de "conjuntar" una serie de prácticas poéticas, encaminadas a poner en cuestión una o varias concepciones de la poesía de los últimos tres decenios del siglo XX, por parte de una serie de escritores especialmente atentos a la realidad sociohistórica de "este" particular momento y su impacto en la poesía y campo cultural latinoamericano. Tratándose, en el caso argentino, de la sustitución de ese neobarroco transhistórico y transculturizado por un neobarroso, que acentuaría la autoconciencia explícita del lenguaje o, lo que es lo mismo, su materialidad. Retomando los postulados de Rojas, se trataría de una escritura neobarroca que describe, desde el punto de vista formal, la producción de sentido del texto en tanto que "proliferación significante"; mientras que, desde el punto de vista del contenido, "la importancia del cuerpo y de los procedimientos de violencia a los que puede ser sometido y los procesos de subjetividad" (18). Así, no más como una práctica o tendencia que como el contexto reflexivo de la creación artística de la "actualidad", podríamos decir que si hay una escritura neobarroca, tal como la entiende Rojas, ésta se articularía sobre la idea de acumulación y exceso significante, como radicalidad de esa materialidad de la escritura y sus lenguajes abiertos y polirreferenciales, al tiempo que como radicalidad de los procesos de violencia en sus distintas dimensiones y manifestaciones de lo político y lo sexual. Tratándose, en el caso de los autores aquí compelidos, de un "neobarroco de la transgresión", donde la sexualidad emerge como una zona de articulación y tensión para el cuestionamiento de las relaciones entre naturaleza y cultura (una variante más de civilización y barbarie), que en estas poéticas se volverán especialmente visibles al tramarse como un mecanismo discursivo para leer los modos específicos en que la violencia sexual y política se hacen parte de una misma trama discursiva y simbólica. 
A partir de lo anterior, entenderé el neobarroco como un dispositivo lingüístico que establece una propuesta crítica al sistema sociopolítico y cultural en que se insertan (dictadura y postdictadura). En el caso de Perlongher, como intervención/interferencia del discurso político de protesta contra la guerra sucia argentina (1976-1983) y su política de exterminio. En el de Silva, como otredad, en tanto conceptualización de los márgenes territoriales y políticos que ha producido la colonialidad de saber/poder en el Chile postransición. Pues si bien se trata de autores cuyas obras y trayectorias corresponden a periodos diferenciados (mas insertos en esa "constante barroca" contemporánea), me interesa discutir la noción de neobarroco como una ética-poética que privilegia el exceso y la transgresión por la forma de una "textura de vanguardia", que no recusa el coloquialismo más o menos comprometido -que Echavarren tachara como principio de acción para los neobarrocos de Medusario $^{2}-$, en busca de una lengua poética autónoma (neobarroso, portuñol, mapuñol) que exprese los "devenires minoritarios" del mundo social contemporáneo.

\section{NÉSTOR PERLONGHER: LA REVOLUCIÓN NO ES DE LOS OTROS, COMIENZA EN EL PROPIO CUERPO}

Si la obra poética-cronística-antropológica de Néstor Perlongher (1949-1992) ${ }^{3}$ consagró la vertiente neobarroca latinoamericana mediante la práctica de un barroco de trinchera que tiene a la lengua como arma revolucionaria, su neobarroso lúdico-perverso, a la fecha, cuenta como el detonante de un

\footnotetext{
Coincido con Matías Ayala en su crítica de la postura un tanto sesgada de Echaverren de concebir el neobarroco en contra de la lengua coloquial con fines políticos: "El problema de esta oposición (...) es que la retrata como el discurso por excelencia monológico, que se presenta con solo un sentido y que lo tiene sin interacción problemática en el plano fonético, sintáctico, semántico, retórico. La poesía coloquial es como la prosa, como el habla, pura comunicación, sin significante para Echaverren" (40).

La obra poética de Néstor Perlongher incluye los siguientes títulos: Austria-Hungría (1980), Alambres (1987), Hule (1989), Parque Lezama (1990), Aguas aéreas (1990), El chorreo de las iluminaciones (1992) y la recopilación de su poesía reunida en Poemas completos (1997). Entre sus ensayos destacan El fantasma del SIDA (1990), La prostitución masculina (1993) y El negocio del deseo (1999), que luego fueron publicados conjuntamente en Prosa Plebeya (1997) y Papeles insumisos (2004).
} 
modo de ocupar esa lengua como objeto estético, camp ${ }^{4}$ o perfo-político, tanto como el modo de producción de una subjetividad "marica" que hizo suyo el debate y la praxis sobre la diferencia sexual.

Recordemos que frente a la letra limpia y pura, Perlongher optó por la mala palabra, la "escatológica de la letra" o "del retrete", para enfatizar la naturaleza de desperdicio de la lengua, su "boca sucia" (Oubiña). Allí donde la loca sudamericana, callejera y prostibularia -figura anómala que del "gay hiperfeminizado" se desplazaría hacia la imagen espectacular de la artificialidad, el travesti, cuya producción determinaría los "devenires del goce", y la carga emancipatoria de su resistencia política- va a emerger como una superficie donde la constitución política de los cuerpos se hace visible, siendo la ocasión para la pregunta por los "cuerpos del exterminio" (Giorgi) o, lo que es lo mismo, por los mapas de la violencia que propician existencias contra natura o estériles; cuerpos en los que se han cifrado de las maneras más diversas sentidos colectivos y ficciones del cuerpo político, de la nación y la historia. Una de estas ficciones es la que produjo la escritura neobarroca de Perlongher a través de la emergencia del cuerpo de la loca o la marica como un cuerpo residual en el que se lee, inequívocamente, un orden social y sexual que verifica y expone lógicas de violencia y deseo (Palmeiro). Un cuerpo en el que el uso de lo exageradamente femenino -emblema del travestismo-, constituye la puesta en escena de la performance ${ }^{5}$ que operan las super-hembras o hipermujeres de Perlongher; mujereidades, para Siganevich, que no hacen suyo un yo de mujer ni reproducen las máscaras del género en la cultura, a pesar de tener en exceso los detalles femeninos; no desean ser mujeres, sentencia la autora, sino que buscan la representación: "cuando hablamos de representación en relación con la narrativa gay u homoerótica no estamos hablando pura y exclusivamente acerca del modo como se presenta y construye el universo homosexual sino también de la

\footnotetext{
Históricamente, el camp ha sido asociado con la cultura homosexual y con los cuestionamientos que se hacen a la naturalización del deseo. Pero el camp no es solo un estilo o una forma de caracterización con la cual las identidades queer se han hecho visibles, es también una posición de resistencia situada en prácticas de representación por medio de las cuales se cuestionan las formas culturales hegemónicas y se constituyen identidades desplazadas, otras.

Entiendo performance, según Butler (2001 y 2002), como una práctica discursiva que instaura y produce aquello que nombra; un conjunto de actos reiterativos, normalizados y controlados por prácticas culturales ritualizadas que materializan la diferencia sexual.
} 
expresión de un sujeto social compuesto por homosexuales, gays, lesbianas y travestis" (Achugar 94). Esto es lo que tematiza esa suerte de "manifiesto drag" del célebre poema, "Por qué seremos tan hermosas", en la provocación paradigmática que representa el camp como figura de artificio y exageración, "ser cada vez más mujer, hasta sobrepasar el límite, yendo más allá de la mujer" (Sarduy, La simulación 56). Esto es, el devenir como un mecanismo de autoconstitución o autoproducción del yo mediante el uso de la máscara, el disfraz y el maquillaje, que bajo el efecto del trompe l'oeil daría lugar a ese artificio barroco denominado por Sarduy como la simulación. Proceso por el que es posible la producción del "travesti humano", como esa pulsión ilimitada de metamorfosis o transformación, y que no se reduce a la imitación de un modelo real determinado, sino que "se precipita en la persecución de una irrealidad infinita (...), irrealidad cada vez más huidiza e inalcanzable" (58). Así, leo "Por qué seremos tan hermosas", como el "hecho mismo del travestismo" en tanto producción del travesti humano, pero también como un manifiesto del nomadismo del deseo, en que el kitsch popular del sujeto marica perlonghereano llega al ridículo para producir un efecto cómico-trágico:

\author{
por qué seremos tan perversas, tan mezquinas \\ (tan derramadas, tan abiertas) \\ y abriremos la puerta de calle al \\ monstruo que mora en las esquinas, $o$ \\ sea el cielo como una explosión de vaselina (...) \\ por qué seremos tan pizpiretas, charlatanas \\ tan solteronas, tan dementes (...) \\ por qué seremos tan despatarradas, tan obesas \\ sorbiendo en lentas aspiraciones el zumo de las noches \\ peligrosas \\ tan entregadas, tan masoquistas, tan \\ -hedonisticamente hablando- \\ por qué seremos tan gozosas, tan gustosas (...) \\ por qué seremos tan sirenas, tan reinas \\ abroqueladas por los infinitos marasmos del romanticismo \\ tan lánguidas, tan magras (58-59).
}

En el poema se hace presente la figura de la marica escandalosa, desestabilizadora de los modelos estándares de masculinidad y femeneidad. Una figura desafiante del orden social, familiar y policial, que Palmeiro relaciona con la militancia 
política de Perlongher en el $\mathrm{FLH}^{6}$ argentino, y su revolución anarquista en el orden del deseo: "Los textos de Perlongher, en particular, defienden a la mariquita como resistencia contracultural contra el machismo, en la medida en que la marica asume voluntaria y solidariamente los atributos de la mujer: devenir mujer como fuga hacia lo menor" (14). Pero también se trata de la visibilización de una cultura de la performance de la feminidad gay, en torno a la que se construyó la estética camp (Sontag); estas hiper-mujeres, "tan hermosas", son el ejemplo radical de una producción de la feminidad a través de la repetición ritualizada de las performances de género, valga decir, de la mascarada ${ }^{7}$ que está a la base del concepto de simulación en Sarduy.

De este modo, el poema elabora la ficción de un autoanálisis como un monólogo dramático, donde el hablante femenino colectivo -nosotrasinterroga sobre ese modo de ser particular que se expresa en las diversas y específicas manifestaciones del travestismo de las locas como extremo del patetismo kitsch de la contra-cultura gay, que, en este caso, es asumida en el orden de los cuerpos travestidos y, por tanto, de acuerdo con la retórica del tatuaje y del maquillaje sarduyanos, proclives al efecto neobarroco de la simulación. Las locas o maricas son aquí una parodia del simulacro de la femeneidad con todos sus atributos estereotípicos: debilidad, fragilidad, torpeza, ingenuidad, banalidad. De allí que como práctica camp, el poema

$6 \quad$ La sigla corresponde al Frente de Liberación Homosexual (1971-1976), heredero del grupo Nuestro Mundo (1969), fundado en Buenos Aires en 1971 por Héctor Anabitarte, como una asociación izquierdista y revolucionaria en defensa de los derechos homosexuales. Un análisis en profundidad sobre las complejidades de articulación de este movimiento se encuentra en Rapisardi 2008.

Convenga tener presente la idea de feminidad como mascarada, teatralización, disfraz o juego de roles: "La feminidad puede ser asumida y llevada como una máscara, al mismo tiempo para disimular la existencia de la masculinidad y para evitar las represalias" (Preciado 35). El género será descrito entonces como una máscara tras la que solo se oculta otra máscara, una imitación detrás de la que se esconde otra imitación, "el original aparece así como una naturalización retrospectiva de la máscara. Una naturalización que no es sino el efecto de un proceso político de normalización" (55).Teresa de Lauretis, por su parte, piensa el género a partir de Foucault como "tecnología del sexo", y propone que en tanto representación, género es el producto de variadas tecnologías sociales y de discursos institucionalizados, de epistemologías y de prácticas críticas y de la vida cotidiana. El género no es una propiedad de los cuerpos o algo originalmente existente en los seres humanos, sino "el conjunto de efectos producidos en los cuerpos, los comportamientos y las relaciones sociales, por el despliegue de una tecnología politica compleja" (68). 
cree un espacio de visibilidad propio a la cultura marica a través del reciclaje y el uso paródico del modelo más cursi y estereotípico de la feminidad.

Pero de la feminidad performática al devenir-mujer de las resistencias micropolíticas, hay un proceso tanto de sexualización del cuerpo como de articulación solidaria de alianzas políticas, con aquellas "existencias contra natura", anómalas, desviadas de la hetero-norma y de los patrones de la dominante cultural. Lo que Palmeiro explica al variar el concepto mismo de devenir: "lo que podríamos actualizar como transvenir (devenir trans: atravesar las barreras del género) y contravenir (devenir contracultural, quebrar las leyes de la individuación)" $(22)^{8}$. Lectura que permite establecer los alcances de las políticas de la diferencia sexual, expresadas en la perspectiva de lo queer $^{9}$, que, como se sabe, no se restringe a designar categorías de orientación sexual (generalmente hombres gay y mujeres lesbianas), sino que implica dimensiones que no pueden ser subsumidas bajo el género y la sexualidad: "maneras en que raza, etnicidad, nacionalidad postcolonial se cruzan con estos y otros discursos que constituyen y fracturan las identidades" (Sedgwick 8-9).

Por otra parte, la voz colectiva que permea desde este lugar de enunciación la posibilidad de expresar otra "comunidad potencial", de forjar los medios de "otra conciencia" y otras "sensibilidades de alianza sexual y social" (Deleuze y Guattari 30), activa en el poema la premisa de una "literatura menor", donde cada problema individual se conecta de inmediato con el

\footnotetext{
Palmeiro aclara la diferencia entre ambos términos: "La idea de devenir mujer o devenir homosexual puede leerse, en el contexto de los debates contemporáneos de los estudios queer más radicalizados, a la luz del concepto de transgénero como instancia de conflicto anti-identitaria y como proceso de fuga de las inscripciones de género; de ahí el concepto de transvenir. En su acepción más amplia, la categoría de transgénero no apunta solamente a las personas que asumen un género que no es el que les es asignado al nacer (...), sino al proceso mismo de subversión performativa (...) de los límites del género. Entonces si el concepto de devenir, en la historia de la filosofía, se basa en la variabilidad esencial de las cosas en su proceso de permanente transformación, el concepto de transvenir enfatiza los límites que se atraviesan en el proceso de mutación. Se dirigiría, más estrictamente, al cuestionamiento de las normas genéricas en el contexto de los debates queer que en la actualidad tienen a la población trans como eje del conflicto articulado en torno a la desigualdad y la diferencia" (24).

Sigo aquí la caracterización de Eve Sedgwick sobre lo queer como una marca resemantizada de la diferencia sexual: "aquello que está dislocado, fuera de lugar, como en el caso de lo lésbico, homosexual, bisexual o travesti; una posición que rebasa la política de la identidad y que se asocia de manera más cercana al descentramiento posmoderno del sujeto, y que trata de revalorizar esta diferencia sexual" (24).
} 
macrorrelato de la política; es decir, donde todo adquiere un valor colectivo y desterritorializado respecto de la lengua/cultura mayor o dominante a la que perturba -en este caso, es clave el uso del dialecto portuñol dentro de la oficialidad que implican el territorio geográfico-cultural del español y el portugués como lenguas mayores u oficiales-.

La voz maruch ${ }^{10}$ de este hablante colectivo marica se sitúa en un lugar de crítica frontal, asumiendo el estereotipo gay "amariconado" desde su cuerpo tatuado/tajeado ${ }^{11}$ para atacar por medio de la pregunta retórica "¿por qué?, y así poner en entredicho esa suerte de "encanallamiento" del sujeto frente a los modelos de la sexualidad política y moralmente establecida, correcta. "Por qué seremos tan hermosas" plantea un ejercicio de devenir-mujer (trans -y contra- venir) en la reiteración de la pregunta insidiosa "por qué seremos tan", donde el sujeto no se define por una identidad objetiva, sino por una serie de atributos en tanto gestos hiperbólicos del estereotipo femenino que caricaturiza. Detengámonos en los adjetivos que se mencionan: "perversas", "mezquinas", "derramadas", "abiertas", "sentadoras", "bonitas", "pizpiretas", "charlatanas", "solteronas", "dementes", "disparatadas", "brillantes", "despatarradas", "obesas", "entregadas", "masoquistas", "gozosas", "gustosas" (portuñol de "gostosas"), "superficiales", "ligeras", "sirenas", "reinas", "lánguidas", "magras", etc. Tratándose de una "proliferación significante" de atributos o cualidades que determina los rasgos de ese colectivo como un "crossdressing camp", que se produce a partir del rescate y "trasheo de un

10 Berta López define así la categoría: “(...) la lengua marucha, que no es sino la creación de un lenguaje propio, dueño de una intensidad que trae a la superficie una marginalidad de naturaleza sexual y donde el sujeto de la enunciación, situado en el margen de la sociedad, se ve imposibilitado de escribir como los maestros de su lengua, por lo que debe explorar otros medios lingüísticos, expresar otra sensibilidad y otra línea de acción que permite nombrar, sentir y vivir el amor entre personas del mismo sexo. Esta lengua homoerótica, homosexual 'desterritorializa' el amor heterosexual e implica no sólo un programa vital sino también un proyecto político" (125).

11 Sobre la estética del tatuaje y el tajo, comenta Adrián Cangi: "si la inclinación al tatuaje robustece la pulsión ornamental, la pantomima y el travestismo (...), la acción de tajear nos expone ante la pulsión destructiva y el mundo de sus desechos, profundamente ritual y conectora entre la lengua y el cuerpo, entre la inscripción y la carne (...) el tatuaje satura de artificio mimético y efímero -a la manera del maquillaje- las superficies del cuerpo, en una densidad compulsiva, hipertélica, amanerada y de fasto, con propensión a lo definitivo. El tajo, sin embargo, -violencia reprimida del instinto, ritual efímero con su aire de provisionalidadconsigue expresar los dezhechoz al recuperar en el gesto el 'jaleo' y sus apetitos y pasiones" $(72-73)$. 
léxico moralizante, regulador de la femeneidad tradicional" (Palmeiro 1617). La exaltación de ese tono subversivo que polemiza con los regímenes de dominación, represión y censura es lo que enfatiza, de este modo, la pregunta retórica "Por qué", que, a su vez, funciona como aliteración para establecer el ritmo aluviónico y envolvente del poema.

Perlongher sabe bien que violentar el lenguaje es hacer que éste agreda. Y, tal como afirma Oubiña, el lenguaje agrede cuando se expresa con el cuerpo (con las partes bajas del cuerpo, con lo excrementicio, con lo sexual), porque eso es lo que debió excluir para constituirse. De modo que, frente a los imperativos de "limpieza, orden y belleza" que "ocupan una posición particular entre las exigencias culturales" (Freud 37), Perlongher pone el cuerpo y la voz de "los grandes apetitos" en una práctica sexual desbordada que oblitera todo vínculo entre higiene y gramática. Ese vínculo que, en la visión de Laporte, sostiene la "cloaca máxima del Estado" en el ideal de limpieza y de una lengua pura, capaz de controlar y jerarquizar las funciones del habla y del cuerpo, simultáneamente. Pero aquí no se trata de hablar del cuerpo, sino de "poner el cuerpo" (para la política, para la literatura, para la antropología). Toda la producción de Perlongher puede ser pensada como una poética y una política del cuerpo desterritorializado por un deseo/pasión de abolición, "contra toda institucionalización identitaria, jerarquizante y ordenadora" (Palmeiro 9). De ahí su lucha como la de un doble cuerpo perverso: el de la escritura y el de la acción política, que estéticamente buscaría la correspondencia entre los actos "finales" del cuerpo y los movimientos "extremos" de la escritura.

En el poema "El polvo"12, Perlongher elabora esta relación de modo tal que cuerpo y palabra logran articular un diálogo desde la distancia (camuflada) en la impersonalidad de un perverso "superyó" como alteridad que produce la visión introspectiva del sujeto; tratándose de un poema que interroga por la posibilidad de que la opresión, el castigo, la vejación, puedan llevar a la experiencia del éxtasis y el goce:

12 El título sugiere al menos tres posibilidades del vocativo "polvo": "como maquillaje, artificio femenil, máscara, simulacro; polvo como metáfora bíblica de la muerte (que en Perlongher estará siempre ligada a la sexualidad) y finalmente, según el argot, como acto sexual, coito (...) el poema es prácticamente el relato de un acto sexual. Y solo en ese acto es posible hablar en femenino, un performativo devenir trans (transvenir) de la marica, es ahí que el cuerpo degenera en otro, o transgenera" (Palmeiro 14-15). 
En esa encantadora soledad

-oh claro, estabas sola!-

en esta enhiesta, insoportable inercia

es ella, es él, siempre de a uno, lo que esplende

ella, su vaporosa mansedumbre o vestido

él, su manera de tajear los sábados, la mucilaginosa telilla de los sábados

la pared de los patios rayada por los haces de una luz encendida a deshora

ceniciento el terror, ya maculado, untuoso en esas buscas

a través de los charcos

los chancros repetidos, esos rastreos del pavor por las mesetas

del hechizo

rápidamente roto

esos destrozos recurrentes de un espejo en la cabeza de otro

espejo

o esos diálogos

"Ya no seré la última marica de tu vida", dice él

que dice ella, o dice ella, o él

que hubiera dicho ella, o si él le hubiera dicho:

"Seré tu último chongo" -y ese sábado

espeso como masacre de tulipanes, lácteo

como la leche de él sobre la boca de ella, o de los senos

de ella sobre los vellos de su ano, o un dedo en la garganta

su concha multicolor hecha pedazos en donde vuelcan los carreros

residuos

de una penetración: la de los penes truncos, puntos, juncos, la de los penes juntos

en su hondura -oh perdido acabar

albur derrame el de ella, el de él, el de ellaél, o élella

con sus trepidaciones nauseabundas y su increíble gusto por la asquerosidad

su coprofagia ${ }^{13}(31-2)$.

13 Téngase en cuenta la distinción terminológica entre chongo y marica. Mientras este remite al homosexual afeminado, aquel se refiere al varón masculino no identificado como homosexual que eventualmente mantiene relaciones homoeróticas (Palmeiro 13). 
La abyección se presenta en el poema articulando esa estética del tajo que reconstruye la visión del cuerpo "en su coprofagia", la putrefacción, el detritus; el sujeto que literalmente se alimenta de excrementos o desechos, en ese contacto que sugieren los penes juntos durante el acto sexual homoerótico masculino. En lo que se hace carne la retórica barroca del objet parure y la confusión/fusión pronominal como señalamiento de los "transvenires en un flujo extático": "el éxtasis sexual aparece como modo de salirse de sí, de confusión, de borramiento de los límites del sujeto en una fusión con otro cuerpo" (Palmeiro 15). Ese contacto que es roce, escarceo, penetración dolorosa, violenta, pulsión destructiva, aunque, al mismo tiempo, ritual y conectora entre la inscripción y la carne, masacre de tulipanes, violencia reprimida del instinto, experiencia del goce y la pasión; esa fuerza de la violencia del cuerpo contra o sobre la piel, fascina, seduce, atrae. El albur derrame, con sus trepidaciones nauseabundas y su increíble gusto por la asquerosidad, es atraído hacia otra parte "tan tentadora como condenada". Allí donde sublimación y devastación del cuerpo violentado hacen posible que la opresión se transforme en goce.

¿Él o ella? ¿Se trata de un mismo cuerpo perseguido por la obscena gula erótica sexual de la humanidad?, ¿un cuerpo que porta en sí los significantes biopolíticos de la hetero-norma: masculino/femenino? En esa conjunción él/ella -cuerpo y escritura-no hay lugar para los sexos ni la diferenciación genérica, cuando los cuerpos ya han devenido otros; y en ellos solo puede actuar la violencia del deseo que es la única fuerza operante, presencia o acontecimiento puro; lo que "esplende" frente a la inercia o la cotidianeidad de lo que aparenta ser pero no es ${ }^{14}$. En "El polvo", el deseo metaforiza la materialidad de los cuerpos anatómicamente diferenciados, objetos de la cosmética travesti: mansedumbre y vestido, la de ella; acción viril y falocéntrica,

14 Valga recordar que es contra esta imposición del sistema sexo-género (hombre-mujer/ masculinidad-feminidad) que se pronuncia Beatriz Preciado en su Testo Yonki, cuando sostiene que la modelización de la subjetividad consiste en una programación del género que permite producir sujetos que se piensan y actúan como cuerpos individuales, que se autocomprenden como espacios y propiedades privadas, con una identidad de género y una sexualidad fijas. La autora rebate la idea de que el género sea solo un concepto, una ideología o una performance: "la certeza de ser hombre o mujer es una ficción somatopolítica producida por un conjunto de tecnologías de domesticación del cuerpo, por un conjunto de técnicas farmacológicas y audiovisuales que fijan y delimitan nuestras potencialidades somáticas funcionando como filtros que producen distorsiones permanentes de la realidad que nos rodea" (89). 
la de él, "su manera de tajear los sábados", en alusión al modo concreto de la sexualidad anal de las prácticas homoeróticas masculinas.

El sujeto abyecto se interroga, se mira, se autoindaga en esa sensibilidad particular, única, de la abyección, la que no deja de ser cursi en la memoria de los encuentros fugaces e intempestivos, atravesados por esa violencia que fascina, por ese don repulsivo del dolor, el desgarro del cuerpo desmembrado, ceniciento el terror, ya maculado, untuoso en esas buscas a través de los charcos... Una alquimia que transforma la pulsión de muerte en soplo de vida. Por eso quien habla en "El polvo" se halla en esa suerte de crisis narcisista que atestigua lo efímero del roce violento con/contra el cuerpo, los chancros repetidos, esos rastreos del pavor por las mesetas del hechizo. Pavor que es la fascinación del sujeto deseante por la violencia sublime de ese contacto desgarrador cuerpo a cuerpo, en ese instante mágico del hechizo, pero rápidamente roto...

Cuando Perlongher propone la mezcla de géneros sexuales, invocando la figura del andrógino (que combina lo masculino con lo femenino en el espacio de un solo cuerpo), o la de los travestis (que juegan con la representación invertida de la sexualidad), nos recuerda que en todos los casos se trata de cuerpos que constituyen superficies o espacios donde se cruzan e invierten signos-marcas culturales y sociales de $l o$ masculino/femenino. El cuerpo se convierte, así, en un espacio donde se inscriben los sentidos que ha configurado el sistema simbólico de la sexualidad, que es decir el lenguaje como producto de una convención socio-cultural. De ahí la impronta estéticopolítica del devenir como propuesta de una zona de intercambio o transacción entre múltiples estados de autorrealización del yo; estados dialógicos de la autoconstitución del sujeto que estarán siempre atravesados por procesos y mecanismos de violencia sexual y política.

\section{ANTONIO SILVA: LA POESÍA NO SE ESCRIBE SE DISPARA}

Uno de los tópicos que resulta más relevante en la poesía del joven poeta chileno Antonio Silva (1970-2012) ${ }^{15}$ es la marginalidad sexualizada de los cuerpos biopolíticamente asignados como femeninos. Una marginalidad que

15 Conforman su obra tres libros de poesía: Andrógino (1996), Analfabeta (2000) y Matria (2007). 
se ve reforzada por el énfasis de la cosmética travesti, alegorizada, del kitsch popular, de sus protagonistas maricas, prostitutas, travestis: la analfabeta, la temporera, la india travestida de selva lírica, la bataclana, la ñusta, precolombina del amor. Tratándose de cuerpos biológicos que aluden a una alteridad de esta naturaleza (la accidentalidad de un sexo), como de cuerpos producidos artificialmente por la retórica y práctica del travestismo - (como se deja leer en el apelativo "lloicas en el abrevadero", que titula una de las secciones de Matria $^{16}$, , y donde la figura del andrógino aparecerá como la marca de una total disolución de las identidades de género.

Tal como veíamos en Perlongher, lo que Silva hace ver con estas figuraciones estético-políticas del devenir mujer y travesti es la vivencia sexual, periférica y marginal, de una serie de sujetos tachados por las biopolíticas de control del cuerpo y las identidades de género que imponen los sistemas de control sobre ellos (el diagnóstico clínico y familiar-social de la anomalía), siendo en Analfabeta (2000) donde el sujeto poético de Silva define una postura abiertamente disidente contra la oposición binaria masculino/femenino, al preguntarse por el lugar de una voz, por una lengua, una indumentaria y una nación, a la que no logra ajustarse. ¿cómo hablo?, ¿ qué lengua-moneda sirve para el intercambio simbólico social de la lengua?, ¿con qué alfabeto descifro mi otro, ese que no soy, ni éste ni aquélla?, interroga Carmen Berenguer en el prólogo del libro.

"Minueto para una india/descuartiza de un cuerpo al látigo de Santo Colón" (13). Así comienza el poemario, aludiendo a la situación de "violencia fundacional" que ha dado origen a la "colonialidad del poder" (Quijano) como consecuencia del "descubrimiento/invención de América", pues tal como señala Raúl Zurita, Silva nos recuerda que en la violencia original del idioma "imperial" ya estaba prefigurada la violencia racial, social, económica, política, que atraviesa la historia de estas "ex-colonias":

16 El poemario contiene seis secciones no numeradas: la primera sin título y la última correspondiente a una cita de Jean Genet: "Poner a cubierto todas la imágenes del lenguaje y utilizarlas, pues están en el desierto, adonde hay que ir a buscarlas" (79), donde se explora la técnica del poema encontrado o ready-made. Las intermedias se titulan, respectivamente: el museo de la pobreza (21), lloicas en el abrevadero (39), un beso para papá (55) y simulando aprendi a ser verdadero (69). 
Estuve sentada en mi lengua por siglos

Ora despierto por la antinatural América

Voy con sonido de Cuzco, Mazatlán, Fuego de la Tierra

Ataviada de neones; artificio de jardín para la analfabeta (13)

El artificio del jardín de la analfabeta será el de la apropiación de las lenguashablas territorializadas dentro de un mismo imaginario de dominación y conquista (Cuzco, Mazatlán, Fuego de la Tierra), para articular en su captura los trazos del mestizaje y la hibridez cultural, cual huella de su humillación más represiva "al recibir una lengua ajena y dominante" (Berenguer 8), que por esta misma razón será siempre memoria de la violencia histórica que significó su implantación.

El poema enfatiza la condición del femenino como marca de ese proceso de violencia simbólica que construye el propio sistema discursivo de la lengua, y la violencia sistémica ${ }^{17}$ de los procesos de mestizaje y aculturación que padece el sujeto marginal, subalterno, desde su condición étnica y de género, mujer e indígena:

Mi Ñusta castra el parloteo de cristianos que no

Poseen memoria

Y arrastra en la estridencia de sus ojos la fatalidad del universo (...)

Y en la animadversión de los sentidos borda un traje de fiesta y lepra

Mi lengua, bilingüe de acrobacias

gotea canciones en el ácimo de tus labios

Mi sexo se traduce a monosílabos

a un trompe indagando en la memoria de tu sonido (...)

Soy lengua diezmada -toda España en mis hombros-(Analfabeta 17-18)

Mi lengua bilingüe de acrobacias destaca la situación de "diglosia cultural" (Lienhard) en tanto práctica asimétrica de bilingüismo, esto es, de relaciones jerárquicas entre lenguas de prestigio social diferenciado: "mi Nusta castra

17 Utilizo las categorías de Slavoj Žižek (2009), de "violencia sistémica", como aquella que refiere a las consecuencias del funcionamiento de los sistemas económico y político, y, por lo tanto, a la violencia inherente a las condiciones del capitalismo global. Y "violencia simbólica", como aquella aplicada al uso y las formas del lenguaje, que determinan la imposición de cierto universo de sentido y representación de la memoria y experiencia de los sujetos excluidos o subalternos. 
el parloteo de cristianos que no/poseen memoria" (17). Los monosílabos que encarnan la sinécdoque del sexo del otro no llegan a ser audibles para el sujeto dominante, (neo)colonizador; por lo que la comunicación será siempre una operación trunca o fallida. No obstante, ese despojo de la voz en el canto elabora la figuración de lo menor (lengua política, desterritorializada y colectiva), donde la memoria de la otredad - de la ñusta, princesa virgen de sangre real en el imperio incaico- se hará audible y comunicable al operar no solo como representación de un grupo social marginado, sino también en tanto se inscribe como escritura alfabética, occidental. He allí la premisa de aculturación o mestizaje en que el sujeto subalterno asimila la norma dominante para articular en/desde el sometimiento su propia gramática deconstructiva/decolonial:

A veces me golpearon; es el precio de MY SHE

A veces me besaron; azul intenso penetró el corazón.

Soy un cuerpo intervenido por el desprecio

aún así tengo neumas que marchitan el destino de la voz,

espejo para reír de labios argentos

una vocal atravesada en mi lengua

un idioma domesticado para la castración (...)

Yo la analfabeta, la precolombina del amor

(Analfabeta 15, el destacado es mío) ${ }^{18}$.

Desde ese idioma "domesticado para la castración", el sujeto despatriado de Matria va a asumir la "lengua diezmada" de la analfabeta como un lugar de resistencia o como un "índice revolucionario". Esta es la propuesta -como medio y fin-de la lengua mapuñol del sujeto despatriado en tanto restauradora de los vínculos afectivo-materiales de ese universo humano desposeído por la impronta de la "herencia colonial" que lo atraviesa.

18 En los primeros cinco versos de "MY SHE", la hablante refiere a esa condición del doble que sugiere la idea de mi otro yo, que en este caso es mi otra "ella"; una operación de travestismo o camuflaje de la identidad. En el poema claramente esa otra es una mujer mundana, probablemente una prostituta: “Jamás necesité cantata de sirenas/Jamás pedí asilo en las piernas de Dios/Sólo me contenté con obreros de alcohol valiente/que cada noche al regresar al pueblo deshojaban mi/peluca" (14). La mención de "peluca" como uno de los elementos de la cosmética femenina/travesti permite leer el doble sentido de la expresión, "deshojar la peluca" como referencia al acto sexual, y más precisamente al gesto penetrativo del sexo masculino en el femenino. 
La lengua mapuñol se alza con los atributos del kitsch y la dicción marucha de las locas que veíamos proliferar en la escritura neobarroca de Perlongher, pero a la base de una marginalidad de triple naturaleza: social, étnica y sexual, como expresión de una sensibilidad homoerótica, que, junto a las culturas hibridas entremezcladas en su imaginario, pone en entredicho las relaciones hetero-normativas de poder como un programa vital al tiempo que un proyecto político. Esta lengua, heredera del habla "fétida, enferma" de Analfabeta, lengua homoerótica y bastarda ${ }^{19}$, es también una lengua intercultural y, por ende, de fronteras de diversa naturaleza: étnicas, de género, geopolíticas, sociales y culturales, y va a postular la necesidad de un rito de iniciación al simulacro -o la simulación mediante el artificio retórico de la máscara, el disfraz y el maquillaje - para la vida mutante (travesti, transgénero, andrógina) de los sujetos "invertidos" que alberga en su territorio desposeído y violentado: "Ramera Amancebada de sol Azteca/ Ona Maya Zapoteca araucanita/ Quechua Aimará Naguatl/De sangre mi vestido jamás americana" (10).

En uno de los fragmentos en que se divide el poema "Temporera" (Matria), encontramos la voz de una mujer parturienta, cuya pobreza material la hace asumir todo el castigo social de quien se sabe condenado por el determinismo que impone esta condición de falta y precariedad:

\author{
AL FONDO MI GRITO DE LAS NALGAS DE LA \\ /TIERRA YERBAMOTO RUDA PALTO \\ JARDÍN DE PÚAS YO MARÍA LEVITANDO SIN / \\ CALZÓN \\ SIN AMOR LA MIRADA FIJA EN UN ORGASMO \\ LA CASA TIEMBLA VACA PATE'VACA MARACA \\ / LACHA SUELTA \\ RAMERA AMANCEBADA TEMPORERA \\ EL INCENDIO EL AMOR SE TE FUE \\ YO LA MUERTA LA MESERA LA MAMONA LA \\ / CARA PARTIDA ${ }^{20}$ (26).
}

19 Véase el poema "BASTARDA" de Analfabeta: "como puta de percal y tajos en el alma/lamo el veneno de tu ombligo/(...)/Mi pan en la mesa de los crímenes y santos invertidos/ Ésta es mi habla; fétida, enferma/voy vengo en el OVNI del horror" (25).

20 Se trata de un poema que reescribe la precariedad del sujeto marginal de Analfabeta: "Yo la sarnosa / la polvorienta la cara partida" ("Taxi" 35). 
El énfasis de las letras mayúsculas y remarcadas en negrita destaca las expresiones que profiere esta condena de acuerdo con la doble falta del sujeto anómalo: su condición social de pobreza (temporera) y moral de prostituta (ramera, amancebada). Lo que explica el despliegue de insultos que en jerga popular recaen sobre su anomalía: pate vaca, maraca, lacha, suelta. Faltas que, no obstante, la mujer asimila, aunque en un tono menor, bajándole el perfil del garabato gratuito y fácil en el momento de autorreferirse: "yo la muerta, la mesera, la mamona, la cara partida" (26). La enumeración va amplificando dichas condiciones hasta que, al final del poema, la voz cede el lugar del habla a su alter ego invertido, a su otro yo puesto en cuestión: la temporera travesti que aparece enmarcada en el discurso por el uso de las comillas:
"Soy María Jorquera Melenao pertenezco a esa ralea de mujeres en las cuales se deposita toda la animadver- sión de una moral rudimentaria, sostenida en el ejerci- cio de lapidación y exilio de la concubina" (27).

El sujeto mujer/travesti admite su pertenencia a esa "ralea" de mujeres prostitutas -con cierta nostalgia: "una casta en desintegración total"-, asumiendo las causas por las cuales es objeto de exclusión y lapidación. Su desviación, bien lo sabe, se proscribe, rechaza y castiga, y frente a ello no hay, como en la violencia sublime de Perlongher, posibilidad de pleno goce, salvo, tal vez, de las fantasías compensatorias que proveen la televisión y las figuras más mediáticas del pop.

Las mayúsculas destacan, también, la identidad de los opresores, sus progenitores, los primeros guardianes del orden patriarcal y la moral cristiana conservadora, represiva. Porque la Matria de Silva es la patria de los sin patria, los que primero son expulsados por la sentencia-anatema que emiten los padres contra el hijo "raro" 21 . Los padres, y con ellos, toda la indumentaria material y simbólica que sirve de uso y práctica para el aprendizaje social del género: "mi enagua" y "mi lengua", aquella que se adquiere de forma pasiva y acrítica (y por tanto violenta) como transmisión de la herencia obligada que conduce a la dictadura del nombre, al hablar como si, "me llamo María Jorquera Menelao": "LA LOCA LA PASCUALA LA MENOR

21 Algo que ya se hacía manifiesto en Andrógino, cuando el sujeto, en femenino, confesaba: "la mal nacida me decían/la solitaria y la loca/porque a veces lloraba/al leer poesía" (13). 
/ LA DIEZMADA" (28). Algo que también era motivo de especulación en el poema "Lar" de Analfabeta, que desde el sentido invertido del topónimo "lar" -lugar de afecto y protección; el hogar, la comunidad y la familia-, permeaba su sentido opuesto: la casa desprotegida y sin resguardo, donde solo es perceptible "la huella del horror en cortinas vasos puertas"; allí, donde "el invierno se quedó a vivir en esta casa" (23).

Finaliza este poema con la transcripción de una segunda voz, que no es la de María Jorquera, sino una voz neutra, externa al discurso del personaje, pero que reitera y confirma la visión del anatema social del cual éste ha sido víctima. Se trata de la canción infantil "La niña María", que todas hemos aprendido en la escuela primaria por la pedagogía del género; esa lección que obliga a la niña a bailar, cuando es a ella a quien se castiga si no lo hace:

\section{LA NIÑA MARÍA HA SALIDO AL BAILE \\ BAILE QUE BAILE QUE BAILE \\ Y SI NO LO BAILA CASTIGO LE DARÁN (25-8).}

Situación que también aparecía tematizada en Analfabeta, cuando el sujeto invertía el enunciado del título de la canción que remite al nombre de la niña, "La niña María", por el acto de muerte que representaba para el sujeto esta imposición del baile. El poema se titula, con evidente ironía, "La niña Moría":

Alguien traza cruces cuando ebria me alejo sin amor
Y si no bailo
Castigo me darán

Desnuda discoteque mi cristal

Destello tras destello

Y si no lo bailo

Castigo me darán (26).

¡AH, QUÉ CANTO DE LA MORDAZA!

Si la diversidad de escrituras implica una diversidad de poéticas, resulta clave entender, aquí, que contra la tendencia homogeneizante que puede recaer sobre un corpus de escrituras "gay" u homoeróticas, así como "de mujeres" o de cualquier otro tipo de diferencia, las variables geo-culturales, de raza 
y de clase las atraviesan sin exclusividad ni afán legitimante. Pues lo que se plantea en esta poética es la existencia de una identidad diferenciada de la producción simbólica, realizada desde el horizonte patriarcal (Achugar); lo cual torna compleja la definición misma del objeto que recae sobre el concepto de la diferencia. Tal como en Perlongher, el vocativo $l o c a^{22}$ que utiliza Silva en sus poemarios refiere una manera de inscribir la diferencia sexual, racial y de clase, mas no solo desde una reevaluación de lo marginal, sino también desde un reordenamiento de las políticas de género dentro del mapa cultural de la globalización, para el entendimiento de las nuevas formas de dominio sobre el cuerpo, conducta y pensamiento. Recordemos que en las "sociedades de control" los mecanismos de dominio se vuelven más "democráticos" o más "inmanentes" al campo social, "distribuyéndose completamente por los cerebros y los cuerpos de los ciudadanos, de modo tal que los sujetos mismos interiorizan cada vez más las conductas de integración y exclusión social adecuadas para este dominio" (Hardt y Negri 36). Esto es lo que parece asumir la loca, menor y diezmada de Matria, los valores interiorizados y autoasumidos por las conductas de integración y exclusión social, adecuadas para este dominio "más democrático" de la sociedad de control en que vivimos, y de la que esta mujer forma parte como sujeto anónimo y mediano. Pero también podemos inferir otra lectura a partir del vocativo loca: como un término que, en el disenso, pacta o suelda una identidad desviada como reconocimiento de una pertenencia no obligada a esa ralea de sujetos otros, también anómalos por su condición de pobreza y desviación sexual. Lo cual, sin embargo, no niega la contradicción que expresa en la hablante un deseo de normalidad cuando ruega: "DAME UN HOMBRE UN HIJO UNA MAÑANA" (28). Ese deseo es quizá la conciencia de saber que de otro modo (fuera de lo "normal") es imposible alcanzar un estado de bienestar, reconocimiento y valoración positivos de la identidad tanto sexual como social que se practica al margen de lo políticamente correcto.

Loca que ejercita en mapuñol. El sincretismo prehispánico por el que discurre esta lengua diglósica, intercultural del mapuñol, se expresa en la voz de un yo plural, interétnico y transgénero. No un yo solo de mujer o solo travesti, por cierto, sino la voz del devenir-mujer, el devenir-travesti, el devenirindígena, de las micropolíticas de la producción-intensidad deseante de todo devenir, pues al igual que las hipermujeres "tan hermosas" de Perlongher, 
la mujer indígena de Silva, una santa y una loca que ve (en el sentido de iluminación) el futuro devenido en otra posibilidad de realización para los sin-patria, los sin-historia, será la figuración de una "microfemineidad" (la mujer "molecular" de Deleuze y Guattari) que deviene madre, santa, prostituta, y todas las figuraciones de los "devenires minoritarios"23, que Perlongher explicara intentando responder por qué todos los devenires comienzan y pasan por el devenir-mujer:

¿Por qué? Porque las mujeres ocupan una posición minoritaria con relación al paradigma de hombre mayoritario - machista, blanco, adulto, heterosexual, cuerdo, padre de familia, habitante de las ciudades... (...) Mayoría y minoría no entendidas por cálculo cuantitativo, sino en tanto calidad de dominación: determinación de un patrón a partir del cual se miden las diferencias; se trataría, en otras palabras, de un modo dominante de subjetivación (Prosa plebeya 68-9).

Desde estas coordenadas, Matria elabora una performance lingüística que prolifera en el desvío de las identidades de género, interrogadas por las figuraciones del travestismo (hombre/mujer; patria/matria); de acuerdo con una escritura neobarroca que no teme el rebuscamiento, la cursilería y el desborde en la construcción de un texto estético y político, que tiene una función ética de representación al tiempo que performativa de teatralización o espectacularización desmesurada. Esto es lo que sugiere el verso "Simulando aprendí a ser verdadero", que abre la última sección del poemario con "La vida subjetiva", en que la voz posicionada del sujeto, siempre en lo precario y marginal, revela la conciencia trágica de habitar un cuerpo que no se sabe natural (como la lengua, la identidad), pero que impone, contra toda voluntad, ciertas prácticas de comportamiento sexual: "penetrar y ser penetrado -digo-/es la ley del universo" (36). Se puede decir, también, que se trata de la consciencia trágica de poseer un cuerpo que no se adapta a la "dictadura del deseo" del sujeto biopolíticamente asignado, hombre o mujer. "La vida subjetiva" es tanto el relato de una determinante histórica, política, como la fractura de una memoria personal, aquella que quiere dejar testimonio de

23 Entiéndase minoría en el sentido de "minoritario" no solo como un dato estadístico, sino como un "índice revolucionario", "potencia de transformación política" o "coeficiente de desterritorialización": "lo que define a una minoría no es el número, sino las relaciones internas con el número. Una minoría puede ser numerosa o incluso infinita; e igual ocurre con una mayoría" (Deleuze y Guattari 73). 
un proceso de transformación que ha ocurrido en un plano temporal y que, por tanto, se puede situar en el tiempo: "cuando eras un hombre", aun se trate de un pasado inexacto y un tiempo presente no concluido del todo. Me refiero a una diacro-sincronía que señala el proceso del devenir conforme un acto de simulación, en que el sujeto aparenta ser lo que no es, pero que, como añoranza o anhelo, corre el tupido velo de aquello que se oculta bajo el disfraz ${ }^{24}$ :

\author{
Cuando eras un hombre \\ el sol era un punto amarillo, \\ una ampolleta de fonda \\ en sus córneas de vidrio \\ Y la luna un disfraz menor \\ para cantarle a huérfanos y Serafitus \\ (...) \\ Una tarde me encontré \\ con la vida \\ Y le arranqué sus aros de campesina china $^{25}$ \\ Diseñé unos ojos para contemplar
}

la nueva vihda (73).

Después de la paráfrasis de Rimbaud -"Una noche, senté a la Belleza en mis rodillas. Y la encontré amarga. Y la injurié" (Una temporada en el infierno)-, el verso final, "la nueva vihda", además de la alusión al Zurita de la Nueva vida ${ }^{26}$, es la frase reescrita de un poema de Andrógino: "toda enfermedad se

24 No es casual que este hecho del travestismo convoque no solo a los huérfanos, despatriados, sino también a la figura mutante de la novela de Balzac, Séraphîta (1835), como signo de una totalidad originaria, del hombre primordial, antepasado mítico de la humanidad que encarnaría los dos sexos a la vez.

25 Es posible que Silva esté aludiendo aquí a la china de la tradición prehispánica. De acuerdo al diccionario aymara de Ludovico Bertonio (1612), el término China (cuyo significado extendido coincide con "mujer" o "hembra") designa a la esposa del Supay o diablo. "China Supay Naupa" es literalmente "Diablo hembra vieja"; originaria de la región minera entre Potosí y Oruro, representaba a uno de los siete pecados capitales, la lujuria.

26 La vida Nueva (1994), como un nuevo "canto general" de la naturaleza chilena y sudamericana, ha sido leída como síntesis de su obra precedente por la crítica: "es en La vida nueva donde Zurita relaciona sueño y poesía, desde la comprensión de la literatura como actividad solidaria en la que entran en relación el poeta y su colectividad (...) La publicación de La vida nueva se explica en parte por este nuevo contexto de reflexiones y por la posición de 
transmite con la sangre", así como repetición/variación de uno de los Koan que elabora Silva en el poema homónimo de Matria $^{27}$ : "en la sangre, ese suave dulzor de la VIHDA", y que en Andrógino tematizaba la realidad de un "Trance" hacia el deterioro y la pérdida:

Toda enfermedad

se transmite con la sangre

ya no recuerdo

la delicada lluvia de abril

ni aquellos trances solitarios

por los caminos del bosque

todo fue en anomia

como lo cantan los desesperados

No recuerdo

cuando comenzó el deterioro. (21)

En Matria, esta nueva vihda marca, considerando la intromisión consciente de una letra que se ve pero no escucha, la h, el doble sentido que ella representa: una vida nueva que no es perceptible para "los seres simples y vulgares, los heterosexuales" (88); una vida marcada por el estigma de la muerte o la enfermedad del sida...

Pero si en su arte de la "manicure cosmética y pincelaje", el sujeto travesti de Silva hacía suya la voz marucha del devenir mujer-india-temporeratravesti-homosexual, para cuestionar las determinantes histórico-sociales de la norma-poder, es en "Los maricas" donde se cumple con mayor énfasis esa teatralización performativa de la voz, cuando sintetiza en una suerte de manifiesto estético y político su programa vital del hecho mismo del travestismo: la imagen autoconstruida de un personaje "minoritario" que

Zurita que se percibe a sí mismo como representante y traductor de la voz colectiva" (Galindo 25). Tomando en cuenta esta lectura, es viable pensar la relación de Silva con el proyecto utópico-colectivo de Zurita, y la posibilidad de que en esta "nueva vihda" esté inscrito otro tipo de alianza y proyecto de comunidad para los sujetos "subalternos".

27 En estas operaciones consiste la "textura de vanguardia" que desarrolla el neobarroco de Silva: apropiación de textos, citas literarias, ready-made, el recurso de la frase hecha/ escuchada y la reescritura por recorte, variación y repetición de sus propios versos, así como de otros poetas y escritores nacionales y extranjeros, como Raúl Zurita, Juan Luis Martínez, Stella Díaz Varín, Enrique Lihn, Mircea Eliade, Walter Miller, Arthur Machen, Jean Genet, entre otros. 
aspira a la figuración del andrógino como ser perfecto - de allí la cita inicial de Eliade que antecede al poema: "El andrógino es considerado superior a ambos sexos /Porque encarna la totalidad y por lo tanto la perfección" (Matria 41)-. Pero el marica no es el andrógino, sino su figuración, su estadio de realización potencial, imaginada y proyectada en el deseo del otro. Figuración que permea la imagen espejística de un muchacho periférico que nació "para ser/contemplado, un Adonis alógeno/y poblacional", de acuerdo a su "espureo talento de neón sudaca" (Matria 29).

El poema refuerza la condición doblemente marginada del sujeto marica, antes periférico y marginal, aquel que en Matria representa el homoerotismo en el desarrollo de diferentes estadios de autoconstitución de una identidad a partir del cuerpo (aquí masculino) travesti o marica, insistiendo en las marcas, los gestos, los ritos que destacan la valía de sus "contactos intensos":

Cruzados en un parque

En el filamento de las sombras

Entre destierro y farol

Hacen su entrada coja los maricas

Las bestias de ágata, torcidos e inmundos

Tronchando con sus gestos

El decorado siempre bastardo de una ciudad felina

Los maricas y sus citas

De párpado en párpado, su lenguaje binario

Como polillas siempre atentos a una nueva antorcha

que surja en el vergel nocturno

Uno es la otra la otra es ella en mi y en el otro

Sus pequeños y violentos actos

Paridos en estertor de un circo pobre

En una luminaria se emborrachan los maricas

Y relatan siempre una misma historia

Despatriados los maricas levantan una bandera; un pañolete izado

en la fetidez de la muelas

De la mano van los invertidos

$\mathrm{Al}$ encuentro de matarifes, lumpenaje y soldados

$\mathrm{Al}$ encuentro de mi canto

Al encuentro de un plumaje abanical

Locos y tristes los maricas 
Condenadamente alegres

Indeciblemente bellos, bellos (41-2).

Tal como en "Por qué seremos tan hermosas", la retórica programática de "Los maricas" se lee en las varias menciones y adjetivaciones del vocativo "maricas": "torcidos", "invertidos", "inmundos", "polillas", "despatriados", "bestias de ágata", "su lenguaje binario", "su plumaje abanical", "locos", "tristes", "alegres", "bellos". Nótese, no obstante, que la aproximación al otro pero también a sí mismo se produce por inversión y a su vez fusión de la mirada. El que mira es a su vez lo mirado. Lo otro, lo diferente. Uno es la otra. La otra es ella en mí y en el otro. Ese otro que es en realidad otra; un hombre/mujer (o a la inversa) que se nombra en el plural "ellos", en una fórmula inclusiva e incluyente que avanza hacia el "nosotros" colectivo, desterritorializado y político de los devenires minoritarios y las resistencias micropolíticas; allí donde es posible la emergencia de otra comunidad potencial, de otra conciencia y otra sensibilidad...

\section{A MODO DE CONCLUSIÓN}

Desde las teorías del arte, los estudios sobre el barroco, los estudios culturales, hasta el debate más reciente sobre las teorías queer y la diferencia sexual, en poesía la escritura neobarroca ha permitido la configuración, a nivel de un corpus textual, de una ética-política que problematiza la profunda inestabilidad y complejidad de un continente híbrido, mestizo, con sus identidades fragmentadas por la herencia colonial y los procesos de violencia fundacional que lo atraviesan en sus más diversas fronteras lingüísticas, geo-culturales y estético-discursivas, desde donde ha sido posible abordarlo como objeto de estudio y crítica. En este horizonte, la posibilidad del devenir que opera en las poéticas neobarrocas de Néstor Perlongher y Antonio Silva -entre muchas otras que pueden inscribirse como parte de un mismo repertorio poético, transgeneracional- no solo constituyen un ejercicio de transgresión a la norma-poder del discurso, la lengua, la historia, la política, sino que construyen las figuraciones/intensidades del deseo más allá de la hipercodificación social del sexo y las sexualidades; allí donde la hegemonía se ve arrostrada por los devenires minoritarios que encarnan las voces de la otredad: mujeres, prostitutas, indígenas, travestis, transexuales... Así opera la visión decolonial del poder en la construcción del conocimiento y las 
subjetividades del margen territorial y político que la contra-patria de Silva moviliza en la matriz de la hibridez cultural de su lengua mapuñol. Así también en el portuñol de Perlongher y el chorreo sintáctico-prosódico de su camp lúdico-perverso, ficción-anatómica de un cuerpo estético-político para el que deseo y violencia serán siempre la voz anómala, invertida, otra, de la protesta y la disidencia.

\section{BIBLIOGRAFÍA}

Achugar, Hugo. "Apuntes sobre la construcción de un nuevo espacio en la literatura homoerótica hispanoamericana”. Estudios 13 (1999): 91-105.

Ayala, Matías. "Estrategias canónicas del neobarroco hispanoamericano". Revista de Crítica Literaria Latinoamericana 76 (2012): 33-50.

Berenguer, Carmen. Analfabeta (Prólogo). Santiago: Cuarto Propio, 2000.

Butler, Judith. El género en disputa. El feminismo y la subversión de la identidad. Trad. Mónica Mansour y Laura Manríquez. Barcelona: Paidós, 2001.

Cuerpos que importan. Sobre los límites materiales y discursivos del sexo. Trad. Alcira Bixio. Barcelona: Paidós, 2002.

Cangi, Adrián. "Ardiente oscuridad”. Lúmpenes peregrinaciones. Ensayos sobre Néstor Perlongher. Rosario: Beatriz Viterbo, 1996.

De Lauretis, Teresa. Technologies of Gender. Essays on Theory, Film and Fiction. London: Macmillan Press, 1989.

Deleuze, Gilles y Félix Guattari. Kafka: Por una literatura menor. Trad. Jorge Aguilar Mora. México: ERA, 1978.

Mil mesetas. Trad. José Vázquez. Valencia: Pretextos, 2010.

Echeverría, Bolívar. La modernidad de lo barroco. México: ERA, 2000.

Freud, Sigmund. El malestar en la cultura. Madrid: Alianza, 1991.

Galindo, Oscar. "Registro y transcripción testimonial en la poesía chilena actual. Lihn, Zurita". Estudios filológicos 38 (2003): 19-29.

Hardt, Michael y Antonio Negri. Imperio. Buenos Aires: Paidós, 2002.

Kristeva, Julia. Poderes de la perversión. Buenos Aires: Siglo XXI, 2006.

Lienhard, Martín. "De mestizajes, heterogeneidades, hibridismos y otras quimeras". Asedios a la heterogeneidad cultural. Eds. José A. Mazzotti y Juan Zevallos. Filadelfia: Asociación internacional de peruanistas, 1996. 57-80.

Link, Daniel. "Cuerpo y memoria en América Latina: el archivo de la loca como sujeto colonial". A contracorriente 1 (2014): 264-277.

López, Berta. "Tengo miedo torero, de Pedro Lemebel: ruptura y testimonio", Estudios Filológicos 40 (2005): 121-129. 
Martínez, Luz Ángela. Barroco y Neobarroco: del descentramiento a la carnavalización del mundo. Santiago: Universitaria, 2011

Milán, Eduardo. "El neobarroco rioplatense", Jaque 134 (1986): 23-24, Montevideo. Entr. Luis Bravo y Elías Uriarte.

Oubiña, David. El silencio y sus bordes. Modos de lo extremo en la literatura y el cine. Buenos Aires: FCE, 2011.

Palmeiro, Cecilia. "Locas, milicos y fusiles: Néstor Perlongher y la última dictadura argentina". Estudios 19 (2011): 9-25.

Perlongher, Néstor. "Los devenires minoritarios”. Prosa Plebeya. Ensayos 1980-1992. Buenos Aires: Colihue, 1997.

Poemas completos (1980-1992). Buenos Aires: Seix Barral, 2003.

Pérez Navarro, Pablo. Del texto al sexo. Judith Butler y la performatividad. Barcelona: Egales, 2008.

Preciado, Beatriz. Testo Yonki. Madrid: Espasa, 2008.

Quijano, Aníbal. “Colonialidad del poder, eurocentrismo y América Latina”. Comp. Edgardo Lander. La colonialidad del saber. Eurocentrismo y ciencias sociales. Perspectivas latinoamericanas. Buenos Aires: CLACSO, 2000. 201-246.

Rapisardi, Flavio. "Escritura y lucha política en la cultura argentina: identidades y hegemonía en el movimiento de diversidades sexuales entre 1970 y 2000". Revista Iberoamericana 225 (1998): 973-995.

Rojas, Sergio. Escritura neobarroca. Temporalidad y cuerpo significante. Santiago de Chile: Palinodia, 2010.

Sarduy, Severo. Escrito sobre un cuerpo. Buenos Aires: Sudamericana, 1969.

La simulación. Caracas: Monte Ávila, 1982.

Sedgwick, Eve. Epistemología del armario. Barcelona: De la Tempestad, 1998.

Siganevich, Paula. “Cómo prender a una pantera?”. Lúmpenes peregrinaciones. Ensayos sobre Néstor Perlongher. Rosario: Beatriz Viterbo, 1996.

Silva, Antonio. Andrógino. Santiago: Concurso Eusebio Lillo, Municipalidad de El Bosque, 1996. Analfabeta. Santiago: Cuarto Propio, 2000. Matria. Santiago: Cuarto Propio, 2007.

Žižek, Slavoj. Sobre la violencia. Seis reflexiones marginales. 2008. Trad. Antonio Antón Fernández. Buenos Aires: Paidós, 2009.

Zurita, Raúl. "El sol negro de Matria”, 2008, documento en línea: http://www.letras.s5.com/ rz270408.html. Consultado el 9 de octubre de 2013. 